onary flow during reperfusion of myocardial infarction: documentation of the no reflow phenomenon with positron emission tomography. J Am Coll Cardiol 1990;16:695-704.

19. Olafsson B, Forman MB, Puett DW, Pou A, Cates CU, Friesinger GC, Virmani R. Reduction of reperfusion injury in the canine preparation by intracoronary adenosine: importance of the endothelium and the no-reflow phenomenon. Circulation 1987;76:1135-45.
20. Kloner RA, Rude RE, Carlson N, Maroko PR, DeBoer LWV, Braunwald E. Ultrastructural evidence of microvascular damage and myocardial cell injury after coronary artery occlusion: which comes first? Circulation 1980;62:945-52.

21. Lim YJ, Nanto S, Masuyama T, Kodama K, Ikeda T, Kitabatake A, Kamada T. Visualization of subendocardial myocardial ischemia with myocardial contrast echocardiography in humans. Circulation 1989;79:233-44.

\title{
Serial angioscopic and angiographic observations during the first hour after successful coronary angioplasty: A preamble to a multicenter trial addressing angioscopic markers for restenosis
}

Percutaneous coronary angioscopy was used in 13 patients in a pilot study to assess the intracoronary changes that occur during the first hour after balloon angioplasty (PTCA). The dilated segment was studied with $4.5 \mathrm{~F}$ angioscopes and with quantitative coronary angiography (QCA) immediately after PTCA and at 15-minute intervais for up to 1 hour after PTCA. Significant progression of intimal dissection and thrombus formation could be demonstrated with angioscopy. These dissections and thrombi remained undetected with angiography, which only showed haziness. Thus through its superior sensitivity to intimal damage and thrombus, coronary angioscopy can reveal important intravascular events that apparently occur even after successful PTCA. The relation of such angioscopic observations to restenosis will be addressed in a subsequent multicenter study. (AM HEART J 1994;128:656-63.)

Peter den Heijer, MD, PhD, ${ }^{a}$ René B. van Dijk, $\mathrm{MD}, \mathrm{PhD},{ }^{\mathrm{a}}$ Hans L. Hillege, $\mathrm{MD},{ }^{\mathrm{a}}$ Milou L. Pentinga, MD, ${ }^{a}$ Patrick W. Serruys, MD, $\mathrm{PhD},{ }^{\mathrm{b}}$ and Kong I. Lie, $\mathrm{MD}, \mathrm{PhD}^{\mathrm{a}}$ Groningen and Rotterdam, The Netherlands

Percutaneous coronary angioscopy is a new imaging method that has reached a stage in its development at which it can be safely and easily added to angioplasty procedures to provide visualization of the in-

\footnotetext{
From the Department of Cardiology, Thoraxcenter, University Hospital Groningen; and brasmus University, Thoraxcenter.

Received for publication Oct. 21, 1993; accepted Jan. 20, 1994.

Reprint requests: Peter den Heijer, MD, Department of Cardiology, Thoraxcenter, University Hospital Groningen, Oostersingel 59, 9713 EZ Gron ingen, The Netherlands.

Copyright 1994 by Mosby-Year Book, Inc.

$0002-8703 / 94 / \$ 3.00+0 \quad \mathbf{4} / \mathbf{1} / \mathbf{5 7 0 4 7}$
}

travascular lumen. It is now possible to examine the entire dilated lesion with an extendable, movable fiber bundle and lens. Although percutaneous transluminal coronary angioplasty (PTCA) is widely established as an effective therapy in patients with coronary artery disease, ${ }^{1-3}$ it is well known that it causes severe disruptions and disturbances of the vascular wall. ${ }^{4-8}$ Vasospasm, ${ }^{9}$ elastic recoil,${ }^{10}$ thrombus formation, ${ }^{11,12}$ and intimal tears and dissection $^{11,13}$ are changes that have been described to occur immediately after PTCA.

The purpose of this study was to investigate whether these changes can be observed by means of 
intracoronary angioscopy even after clinically and angiographically successful PTCA procedures and, if present, to observe by serial imaging whether these changes show progression during the first hour after PTCA. This study served as a pilot study for a larger multicenter study that will address the prognostic significance of angioscopic observations like thrombus and dissection for restenosis. Angioscopy is especially suitable for detecting thrombus ${ }^{14-16}$ and intimal tears and flaps. ${ }^{12,15}$ Quantitative coronary angiography (QCA) has been used to assess the phenomenon of elastic recoil after PTCA. ${ }^{10,17}$ Thus quantitative angiography and angioscopy were combined to acquire optimal information on the intravascular changes that occur shortly after PTCA.

\section{METHODS}

Patients. Thirteen patients who were candidates for elective PTCA were enrolled in this study within 4 months. The lesions that were elected for balloon dilatation had to be located in the midsection of one of the large epicardial coronary arteries without excessive tortuosity to be considered suitable for coronary angioscopy. Only patients who underwent an angiographically successful PTCA $(\geq 20 \%$ enlargement of luminal diameter and $\leq 50 \%$ residual stenosis) without angiographic evidence of dissection and without the need for stent placement or prolonged inflation with an autoperfusion balloon were included. At the time of inclusion, all patients were free of symptoms. All patients had given informed consent before the PTCA procedure.

Angioscopy system. The ImageCath (Buxter, Edwards LIS Division, Irvine, Calif.) angioscopy system comprises a disposable angioscopy catheter, an irrigation system, a light source, and a tuned video system. The angioscopy catheter is a three-lumen catheter with an outer diameter of $4.5 \mathrm{~F}(1.5 \mathrm{~mm})$ that can be introduced into the coronary arteries through a standard 8F PTCA guiding catheter and over a regular 0.014-inch PTCA guide wire. It features a movable optical fiber bundle that can be moved independently from the catheter over a $5 \mathrm{~cm}$ distance and over the same guide wire. During imaging, warmed physiologic saline solution $\left(37^{\circ} \mathrm{C}\right)$ is infused through a distal irrigation port at a rate of 30 to $45 \mathrm{ml} / \mathrm{min}$ by means of a power injector. To obtain an optimal clear image during flushing, a Kraton (Shell Chemical Corp.) distensible, low-pressure occlusion cuff is mounted on the catheter shaft proximal to the irrigation port. The $300 \mathrm{~W}$ xenon light source generates a light temperature of $6300 \mathrm{~K}$. At this light temperature the evenness of the spectral distribution is sufficient for optimal true color imaging. The half-inch charged couple device (CCD) camera provides a high resolution and has an automatic white balance.

Quantitative coronary angiography. Quantitative angiographic measurements were performed with the ImageComm (Santa Clara, Calif.) system. The contrast-filled shaft of the guiding catheter, 2 to $3 \mathrm{~cm}$ proximal to its tip, was used for calibration. Minimal luminal diameter (MLD), reference diameter (RD), and percentage diameter stenosis (\%DS) were calculated with the use of well-validated automated contour detection algorithms. ${ }^{18}$

Procedure. Coronary angioplasty was performed for single discrete lesions in single vessels. Before the procedure, the patients were given 10,000 to $15,000 \mathrm{U}$ of heparin and at 1 hour $5000 \mathrm{U}$ of heparin. The guide wire was left in place, and the balloon catheter was exchanged for the angioscopy catheter. Angioscopy was performed immediately after PTCA and at 15,30, 45, and 60 minutes after angioplasty (Fig. 1). All angioscopic runs were recorded on videotape. At each sequence a single recording was obtained while the angioscope was advanced through the section of interest; another recording was obtained while the scope was withdrawn each sequence took $<5$ minutes. On average, $300 \mathrm{ml}$ of irrigation fluid was delivered to the patient per hour. Cineangiograms taken after intracoronary administration of $0.2 \mathrm{mg}$ nitroglycerin and at standardized projection angles for quantitative analysis preceded each angioscopy session. The guiding catheter and the guide wire were left in situ throughout the procedure, with repeated flushing of the guiding catheter and continuous pressure monitoring at its tip. The protocol allowed repeat balloon angioplasty to be performed if a visually assessed stenosis $\geq 50 \%$ was noticed after the last angioscopy at 1 hour after PTCA.

Angioscopy scoring method. Classification systems of angioscopic images that have been used in earlier studies $^{12,14,16,19,20}$ offered insufficient categories and grades to classify the data that can be obtained with the new device. Furthermore, specific parameters were needed to describe the balloon angioplasty effects on the vessel. We therefore used a classification system with the following items: estimated lumen diameter, dissection (intimal tears and dissection), thrombus, and color of thrombus. All items were scored for 2 to 6 grades or categories (Table I). All videotapes were reviewed by two physicians who were unaware of the angiographic findings. Luminal narrowing was estimated by angioscopy by visual reference to the 0.014 -inch PTCA guide wire that passed through the stenotic lesions. Luminal diameter was classified as grade 2 (narrowing) if, by estimation, the remaining lumen was comparable to the total circumference of three of these guide wires. A larger remaining lumen was classified as grade 1 (no or minimal narrowing). The narrowing was defined as grade 3 (total occlusion) if no or a minimal lumen remained visible around the guide wire. The angioscopic definition for a thrombus was intraluminal, superficial or protruding mass, adherent to the vessel surface, but clearly a separate structure. Additionally, if the diagnosis of white thrombus would be made, the appearance of the mass should be shaggy, irregular, and cotton-wool-like. Angioscopic dissection was defined as visible cracks or tissures on the luminal surface and/or mobile or nonmobile protruding structures contiguous with the vessel wall and of homogeneous appearance with the vessel wall.

A modified version of this angioscopy classification sys- 


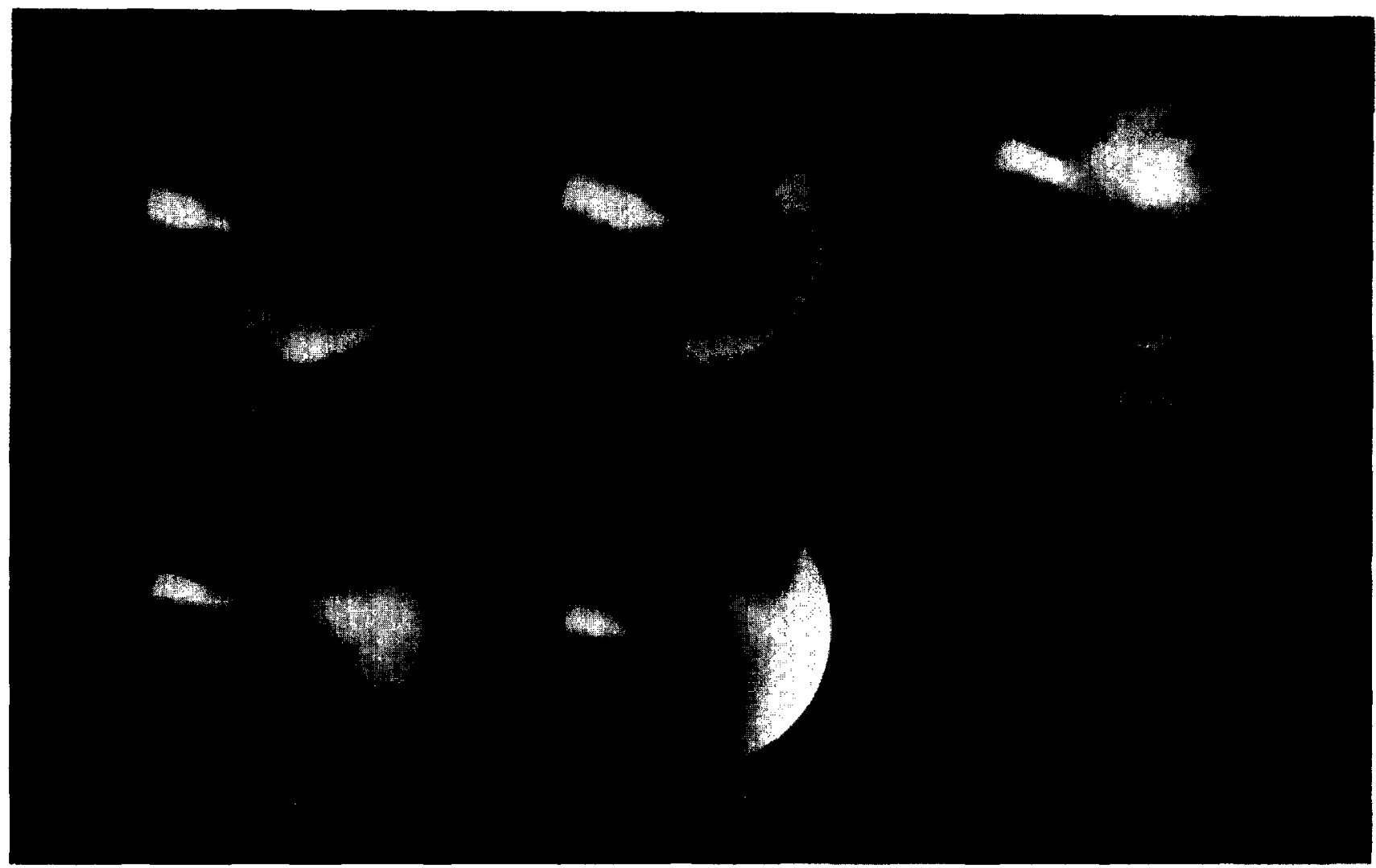

Fig. 1. Serial angioscopic images at $0,15,30,45$, and 60 minutes after PTCA in single patient. Distinct progression in appearance and size of white intima flaps can be seen in this example.

Table I. Classification system and frequency distributions of angioscopic observations during first hour after PTCA. Data are presented as numbers of patients and percentages

\begin{tabular}{|c|c|c|c|c|c|}
\hline & Post-PTCA & $15 \mathrm{~min}$. & $30 \mathrm{~min}$. & $45 \mathrm{~min}$. & $60 \mathrm{~min}$. \\
\hline \multicolumn{6}{|l|}{ Angioscopic lumen diameter } \\
\hline 1: No or minimal narrowing & $5(38.5 \%)$ & $2(15.4 \%)$ & $2(15.4 \%)$ & $2(15.4 \%)$ & $2(15.4 \%)$ \\
\hline 2: Narrowing & $8(61.5 \%)$ & $11(84.6 \%)$ & $8(61.5 \%)$ & $6(46.2 \%)$ & $5(38.5 \%)$ \\
\hline 3: Total occlusion & $0(0 \%)$ & $0(0 \%)$ & $3(23.1 \%)$ & $5(38.5 \%)$ & $6(46.2 \%)$ \\
\hline \multicolumn{6}{|l|}{ Surface disruptions (dissection) } \\
\hline 1: None & $4(30.8 \%)$ & $1(7.7 \%)$ & $1(7.7 \%)$ & $1(7.7 \%)$ & $0(0 \%)$ \\
\hline 2: Small flaps & $8(61.5 \%)$ & $9(69.2 \%)$ & $6(46.2 \%)$ & $4(30.8 \%)$ & $5(38.5 \%)$ \\
\hline 3: Large surface disruptions & $1(7.7 \%)$ & $3(23.1 \%)$ & $6(46.2 \%)$ & $8(61.5 \%)$ & $8(61.5 \%)$ \\
\hline \multicolumn{6}{|l|}{ Thrombus } \\
\hline 1: None & $8(61.5 \%)$ & $6(46.2 \%)$ & $4(30.8 \%)$ & $2(15.4 \%)$ & $1(7.7 \%)$ \\
\hline 2: One-lining thrombus & $3(23.1 \%)$ & $4(30.8 \%)$ & $2(15.4 \%)$ & $2(15.4 \%)$ & $0(0 \%)$ \\
\hline 3: Multiple-lining thrombus & $0(0 \%)$ & $2(15.4 \%)$ & $2(15.4 \%)$ & $2(15.4 \%)$ & $3(23.1 \%)$ \\
\hline 4: Luminal thrombus $<1 / 3$ of lumen & $1(7.7 \%)$ & $1(7.7 \%)$ & $3(23.1 \%)$ & $5(38.5 \%)$ & $7(53.8 \%)$ \\
\hline 5: Luminal thrombus $1 / 3-2 / 3$ of lumen & $1(7.7 \%)$ & $0(0 \%)$ & $2(15.4 \%)$ & $1(7.7 \%)$ & $1(7.7 \%)$ \\
\hline 6: Luminal thrombus $2 / 3-3 / 3$ of lumen & $0(0 \%)$ & $0(0 \%)$ & $0(0 \%)$ & $1(7.7 \%)$ & $1(7.7 \%)$ \\
\hline \multicolumn{6}{|l|}{ Color of thrombus } \\
\hline $0:$ Not applicable & $8(61.5 \%)$ & $6(46.2 \%)$ & $4(30.8 \%)$ & $2(15.4 \%)$ & $1(7.7 \%)$ \\
\hline 1: Homogeneous & $5(38.5 \%)$ & $5(38.5 \%)$ & $5(38.5 \%)$ & $4(30.8 \%)$ & $4(30.8 \%)$ \\
\hline 2: Mixed, multiple colors & $0(0 \%)$ & $2(15.4 \%)$ & $4(30.8 \%)$ & $7(53.8 \%)$ & $8(61.5 \%)$ \\
\hline \multicolumn{6}{|l|}{ Predominant thrombus color } \\
\hline $0:$ Not applicable & $8(61.5 \%)$ & $6(46.2 \%)$ & $4(30.8 \%)$ & $2(15.4 \%)$ & $1(7.7 \%)$ \\
\hline 1: White & $1(7.7 \%)$ & $0(0 \%)$ & $5(38.5 \%)$ & $6(46.2 \%)$ & $9(69.2 \%)$ \\
\hline 2: Red & $4(30.8)$ & $7(53.8 \%)$ & $4(30.8 \%)$ & $5(38.5 \%)$ & $3(23.1 \%)$ \\
\hline
\end{tabular}




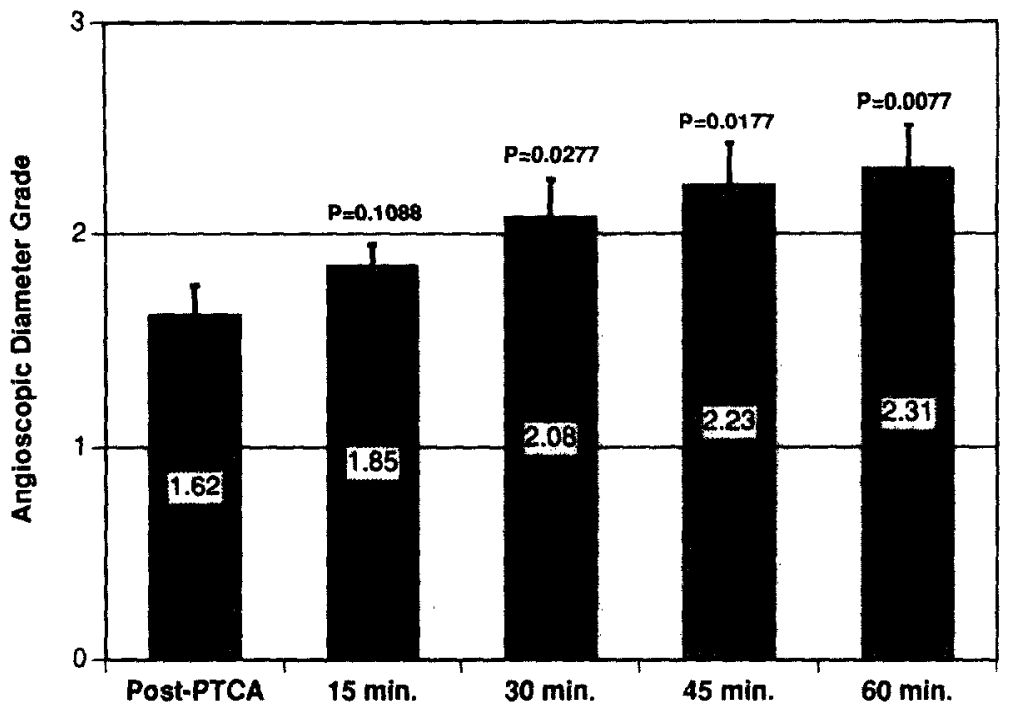

Fig. 2. Mean angioscopic gradings of lesion diameter (description of grading appears in Table I). Numbers are presented as mean $\pm \mathrm{SEM}$. The $p$ values represent comparisons to baseline value immediately after PTCA (Wilcoxon's matched-pairs signed rank test).

tem has been adopted by the European Working Group on Coronary Angioscopy. ${ }^{20 a}$ Intraobserver and interobserver agreements of angioscopic recordings evaluated by this working group were considered acceptable. Intraobserver and interobserver agreement of the angioscopic presence of red thrombus were $91 \%$ and $81 \%$. For dissection, these figures were $87 \%$ for intraobserver and $73 \%$ for interobserver agreement.

Statistical analysis. Both continuous and ordinal data are summarized as mean \pm SEM for simplicity of interpretation. The changes in the study group concerning the angioscopic lumen diameter, dissection, and presence of thrombus from baseline (first observations after PTCA) to 60 minutes after PTCA were compared at baseline with the Wilcoxon rank sum test. The changes in thrombus color and the predominant thrombus color at baseline were analyzed with the McNemar change test. Quantitative analysis parameters were compared with Student's paired $t$ test. No explicit adjustment was made for repeated measurements, which must be taken into account when interpreting the $p$ values. The individual $p$ values are reported. The strength of pairwise association between the angioscopic diameter grading and QCA-derived $\% \mathrm{DS}$ and MLD was assessed with the Spearman's rank order correlation coefficient. All analyses were performed with SPSS PC+ (SPSS Inc., Chicago, Ill.) version 5.0 software. All tests are two-sided. A two-tailed $p$ value of $<0.05$ was considered to indicate statistical significance.

\section{RESULTS}

The frequency distributions of the angioscopic observations during the first hour after PTCA are presented in Table I. The number of patients with an angioscopically visible narrowing at the dilatation site increase at each 15-minute interval. At 1 hour, angioscopic occlusion-defined as no or minimal lumen visible around the guide wire-was scored in 6 of 13 patients. The frequency distributions of dissection and thrombus also reveal a shift toward more pathologic findings after each interval. The colors of the observed thrombi show a tendency from homogeneous colors toward mixed and multiple colors, with white becoming predominant over red. Figs. 2 through 4 show the mean values of the angioscopic grading of lumen diameter, dissection, and thrombus during the first hour after PTCA. The values at 15, 30,45 , and 60 minutes are compared to the baseline values immediately after PTCA to demonstrate any progression in these angioscopically observed changes. Most lesions had some degree of disruption of the vascular inner surface after PTCA, interpreted as grades of intima dissection. Furthermore, there was a significant progression in grading of intima disruption: at baseline immediately after PTCA the mean value was $1.77 \pm 0.17$, with a median value of 2.0 (small flaps); at 60 minutes a mean of $2.62 \pm 0.14$ was scored, with a median of 3.0 (large surface disruptions).

The same trend was observed for the occurrence of intracoronary thrombus after PTCA. The colors of the observed thrombi showed a significant shift from homogeneous at baseline toward mixed at 60 minutes (two-tailed $p 0.0078$ ) and from red at baseline toward white at 60 minutes (two-tailed $p 0.0078$ ). White thrombus was present in $69.2 \%$ at 60 minutes versus $7.7 \%$ immediately after PTCA. Thus the increase in 


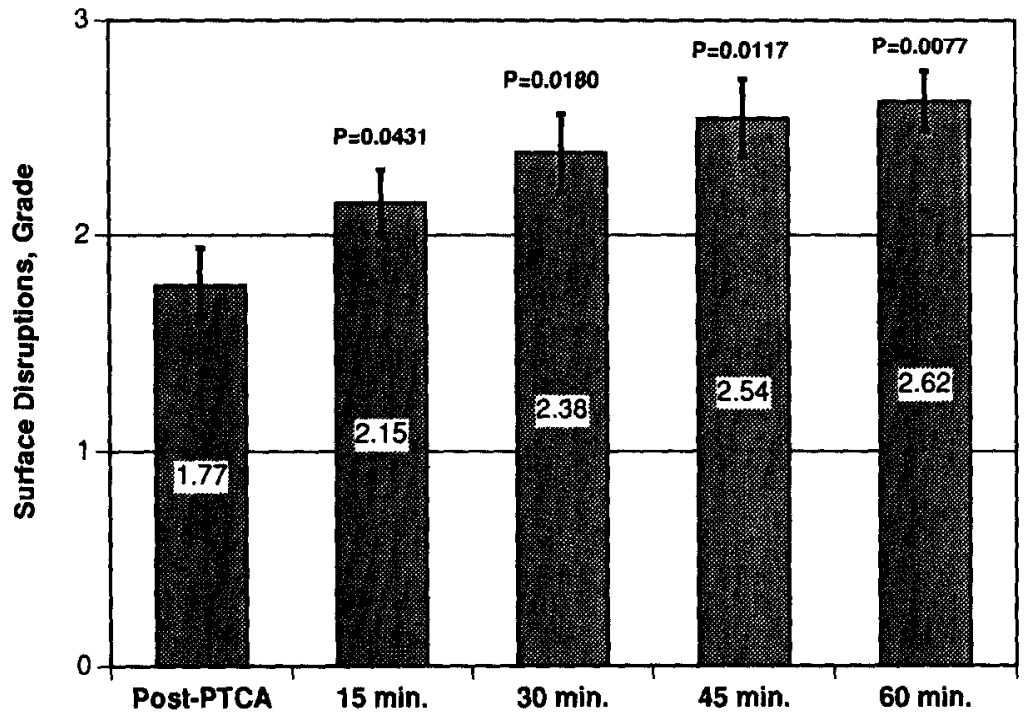

Fig. 3. Mean angioscopic gradings of surface disruptions (dissection) (description of grading appears in Table I). Numbers are presented as mean \pm SEM. $p$ Values represent comparisons to baseline value immediately after PTCA (Wilcoxon's matched-pairs signed rank test).

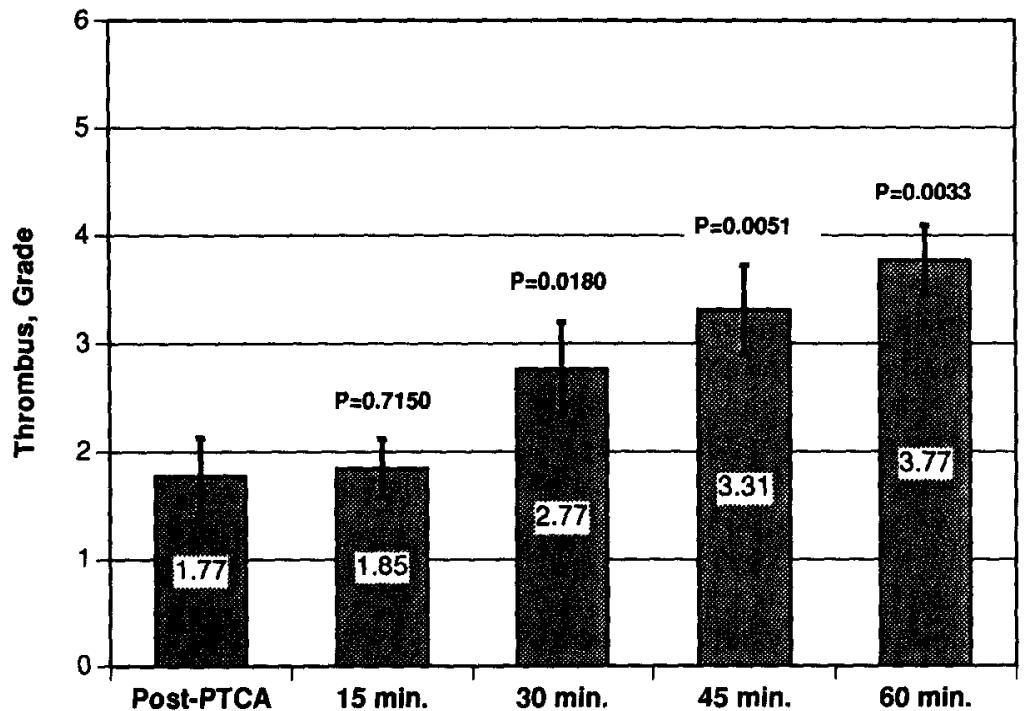

Fig. 4. Mean angioscopic gradings of thrombus (description of grading appears in Table I). Numbers are presented as mean \pm SEM. $p$ Values represent comparisons to baseline value immediately after PTCA (Wilcoxon's matched-pairs signed rank test).

the total amount of thrombus as seen in Fig. 4 can be largely attributed to an increasing incidence of white intracoronary thrombus. Angiography revealed only the haziness of the lesions. In none of these 13 patients were angiographic criteria for either intima dissection or intracoronary thrombus positive on any of the cineangiograms. Although the diameter grading shows a significant change during this first hour, it must be stressed that this finding is based on an essentially nonquantitative and subjective approach.
In contrast, QCA yields objective numeric values of MLD and \%DS. These values are presented in Table II. There appeared to be a significant increase in $\% \mathrm{DS}$ and loss of MLD at 60 minutes. This cannot be attributed to the repeated intracoronary nitrate injections because the RD does not change. The Spearman correlation coefficients for angioscopic diameter grading versus \% DS and MLD are given in Table III. Significant correlations were not demonstrated in this study because the sample size was 
Table II. Quantitative analysis of percentage diameter stenosis, minimal luminal diameter, and reference diameter

\begin{tabular}{|c|c|c|c|c|c|c|c|c|c|}
\hline & $\begin{array}{c}\text { Immediately } \\
\text { after } \\
\text { PTCA }\end{array}$ & $15 \mathrm{~min}$ & $p$ Value & $30 \mathrm{~min}$ & p Value & $45 \mathrm{~min}$ & p Value & $60 \mathrm{~min}$ & p Value \\
\hline$\% \mathrm{DS}$ & $31.35 \pm 18.51$ & $36.39 \pm 15.63$ & 0.233 & $37.90 \pm 10.13$ & 0.192 & $39.25 \pm 13.86$ & 0.097 & $42.56+16.46$ & 0.025 \\
\hline $\operatorname{MLD}(\mathrm{mm})$ & $1.79 \pm 0.49$ & $1.69 \pm 0.50$ & 0.285 & $1.63 \pm 0.44$ & 0.124 & $1.58 \pm 0.48$ & 0.076 & $1.48=0.53$ & 0.011 \\
\hline $\mathrm{RD}(\mathrm{mm})$ & $2.61 \pm 0.34$ & $2.63 \pm 0.30$ & 0.641 & $2.59 \pm 0.37$ & 0.750 & $2.56 \pm 0.36$ & 0.101 & $2.53 \pm 0.37$ & 0.191 \\
\hline
\end{tabular}

Values at $15,30,45$, and 60 minutes are compared to those obtained immediately after PTCA. Values are mean \pm SD.

Table III. Spearman correlation coefficients for angioscopic diameter grading vs percentage diameter stenosis and vs minimal luminal diameter

\begin{tabular}{|c|c|c|c|c|c|}
\hline & Immediately & $15 \mathrm{~min}$ & $30 \mathrm{~min}$ & $45 \mathrm{~min}$ & $60 \mathrm{~min}$ \\
\hline \multicolumn{6}{|c|}{ Angioscopic lumen diameter us percentage diameter stenosis } \\
\hline Spearman correlation coefficient & 0.34 & 0.46 & 0.12 & 0.04 & 0.42 \\
\hline Significance & $p 0.259$ & $p 0.117$ & $p 0.696$ & $p 0.899$ & $p 0.152$ \\
\hline \multicolumn{6}{|c|}{ Angioscopic lumen diameter us minimal luminal diameter } \\
\hline Spearman correlation coefficient & 0.17 & 0.40 & 0.38 & 0.15 & 0.53 \\
\hline Significance & $p 0.581$ & $p 0.177$ & $p 0.902$ & $p 0.626$ & $p 0.063$ \\
\hline
\end{tabular}

$n=13$. Three patients underwent repeat PTCA at 1 hour.

\section{DISCUSSION}

This study established that coronary angioscopy can reveal important intravascular events after balloon dilatation that remain undetected with coronary contrast angiography. Patients with angiographic evidence of dissection after PTCA were not included in the study. The angiograms at $15,30,45$, and 60 minutes of the study group were also free from signs of dissection, although they generally showed some haziness. Only a decrease of MLD and an increase in percentage of stenosis (\% DS) could be demonstrated after 1 hour with QCA. No after PTCA angiograms met the angiographic criteria for intravascular thrombus. On the other hand, with coronary angioscopy, quite dramatic signs of vascular wall damage, large intima disruptions, and thrombi could be demonstrated and put into a grading scale. The finding of this post-PTCA damage, which is in accordance with previous histologic, ${ }^{4,5,8}$ ultrasound, ${ }^{21-23}$ and angioscopic $^{12,24,25}$ studies, underscores the relatively low sensitivity of contrast angiography for intravascular abnormalities.

Some of these intracoronary changes after successful balloon dilatation proved to show progression in time from immediately post-procedure to 60 minutes after the PTCA. Dissections were scored more and with higher grades at each subsequent 15-minute in- terval: grade 3 (large) surface disruptions were present, with frequency increasing from $7.7 \%$ after PTCA to $61.5 \%$ at 1 hour. It does not seem likely that the actual process of intimal tearing and dissection would continue after angioplasty. However, it is conceivable that intima flaps partially detached by the balloon dilatation but lying flush against the inner vessel surface, may gradually move toward the lumen and thus give the angioscopic impression of increasing occurrence and size of these flaps. These dissections may explain the substantial decrease of MLD from $1.8 \pm 0.5 \mathrm{~mm}$ after PTCA to $1.5 \pm 0.5 \mathrm{~mm}$ at 1 hour. This unexpected luminal diameter loss at 1 hour is of comparable order as found at 6 months after PTCA in various restenosis studies, ${ }^{26-28}$ and is consistent with the data of Kimura et al.$^{29}$ but in apparent contrast to studies by Foley et al. ${ }^{30}$ and Hanet et al., ${ }^{31}$ who found, in much larger study populations, no loss in MLD at 24 hours after PTCA. Because to our knowledge no previous studies have reported angiographic and angioscopic appearances at 1 hour after PTCA, the possibility that a transient decrease in luminal diameter during the first hour after PTCA with subsequent recovery could be a real phenomenon must be considered. However, a more plausible explanation may be that, as discussed earlier, repeated passages of the angioscopy catheter may have aggravated dissections that had already been present after balloon dilatation. Although angioscopy is a fairly atraumatic over-the-wire procedure, with di- 
rect visual control of the coaxial alignment of the lens-tip assembly, it must be recognized that the repeated passage of the angioscopy catheter through the dilated lesion may have produced this progression of the dissections. Thus it can be assumed that this loss in MLD has been caused by the observed progressive intima disruptions and that it is an artificially induced deterioration of the PTCA result. It must be stressed that these intima disruptions were only observed by angioscopy, with the angiograms revealing only haziness. Angioscopy did not cause any dissection according to angiographic criteria. Based on the findings, but also on the limitations, of this pilot study, a multicenter study is now being prepared in The Netherlands to address the relation of angioscopic observations after PTCA with restenosis. A major difference will be that angioscopy will be performed only once immediately after PTCA and once at 24 hours after PTCA.

At the present time a major drawback of angioscopy is the absence of quantitative measurement tools. We used a grading scale for angioscopic diameter estimation that proved not to correlate to the QCA measurements of PDS and MLD (Table II). It seems that angioscopy underestimated the remaining lumen because angioscopic total occlusion was scored in 6 of 13 patients at 1 hour after PTCA, although no angiographic total occlusion occurred. Angioscopic occlusion was defined as no or minimal lumen remaining visible around the guide wire. In these six cases, large thrombi or dissections obstructed visualization of the lumen, which apparently is not comparable to a functional or angiographic vessel occlusion. These data confirm that, although angioscopy gives a superior insight in intravascular structures and changes, diameter measurements are currently best left to quantitative angiographic methods. Thus our conclusions concerning the decrease in luminal diameter are drawn from the QCA measurements rather than the angioscopic data on luminal narrowing.

Progressive intracoronary thrombus formation was also observed at angioscopy. Thrombus formation may have been caused by the unusual situation of a guide wire in the artery for such a period after balloon angioplasty. On the other hand, thrombi were only observed developing on the vessel wall and not on the guide wire itself. Progressive intima disruptions may have contributed to platelet aggregation on the damaged endothelium. Until now, thrombus formation after PTCA has not been adequately investigated in patients because the only reliable diagnostic tool for this is coronary angioscopy: angiography gives a gross underestimation of the presence of thrombus. ${ }^{32}$ Thus it cannot be excluded that progressive thrombus formation after PTCA is a real phenomenon, taking place even in heparin-treated patients such as in this study.

Mizuno et al. ${ }^{33}$ reported the angioscopic observation of the growth of copper coil-induced thrombi in dogs. These thrombi started to develop as white, fibrinlike material followed by the appearance of mixed red and white material. Our post-PTCA observations show the same pattern: we observed small red mural thrombi immediately after the balloon angioplasty that may have been present before PTCA. The progression in the total amount of observed thrombi could largely be attributed to the emergence of white and mixed red and white thrombi during the first hour after PTCA. The diagnosis of thrombus is without question if mixed red and white intraluminal masses are observed. Purely white thrombi, on the other hand, may be difficult to discriminate from white intimal flaps, resulting in a potential lack of specificity in identifying these purely white thrombi. Nevertheless, it can be speculated that such a thrombotic process, on a scale too small for angiographic detection, can continue for hours or days after PTCA.

The impact of our findings of angiographically unsuspected intima damage and thrombus formation on acute PTCA complications and late results is presently unknown but in our opinion well worth investigating. We conclude that through its superior sensitivity to detect intima damage and intracoronary thrombus, intracoronary angioscopy can serve as an important diagnostic tool in larger multicenter studies addressing factors influencing primary PTCA outcome and restenosis after initially successful coronary balloon angioplasty.

\section{REFERENCES}

1. Ryan TJ, Faxon DP, Gunnar RM, Kennedy JW, King SI, Loop FD, Peterson KL, Reeves TJ, Williams DO, Winters WJ, Fisch C, DeSanctis RW, Dodge HT, Reeves TJ, Weinberg SL. Guidelines for percutaneous transluminal coronary angioplasty: a report of the American College of Cardiology/American Heart Association Task Force on assessment of diagnostic and therapeutic cardiovascular procedures (subcommittee on percutaneous transluminal coronary angioplasty). Circulation 1988;78:486-502.

2. Block PC. Percutaneous transluminal coronary angioplasty: role in the treatment of coronary artery disease. Circulation 1985;161:V161-5.

3. Hartzler GO. Coronary angioplasty: indications and results. Cardiovasc Clin 1985;15:97-107.

4. Baughman KL, Pasternak RC, Fallon JT, Block PC. Transluminal coronary angioplasty of postmortem human hearts. Am J Cardiol 1981;48:1044-7.

5. Block PC, Myler RK, Stertzer S, Fallon JT. Morphology after transluminal angioplasty in human beings. $\mathrm{N}$ Engl $\mathrm{J}$ Med 1981;305:382-5.

6. Castaneda $\mathrm{ZW}$, Formumek A, Tadavarthy M. The mechanism of balloon angioplasty. Radiology 1980;135:565-71. 
7. Faxon DP, Sanborn TA, Haudenschild CC. Mechanism of angioplasty and its relation to restenosis. Am J Cardiol 1987;60:5$9 \mathrm{~B}$

8. Sanborn TA, Faxon DP, Haudenschild C. The mechanism of transluminal angioplasty: evidence for formation of aneurysms in experimental atherosclerosis. Circulation 1983;68: $1136-40$.

9. Fischell TA, Derby G, Tse TM, Stadius ML. Coronary artery vasoconstriction routinely occurs after percutaneous transluminal coronary angioplasty: a quantitative arteriographic analysis. Circulation 1988;78:1323-34.

10. Rensing BJ, Hermans WRM, Beatt KJ, Laarman GJ, Suryapranata H, Van den Brand M, De Feyter PJ, Serruys PW. Quantitative angiographic assessment of elastic recoil after percutaneous transluminal coronary angioplasty. Am J Cardiol 1990;66:1039-44.

11. Waller BF, Gorfinkel HJ, Rogers FJ. Early and late morphologic changes in major epicardial coronary arteries after percutaneous transluminal coronary angioplasty. Am J Cardiol $1984 ; 53: 42-47 \mathrm{C}$

12. Uchida Y, Hasegawa K, Kawamura K, Shibuya I. Angioscopic observation of the coronary luminal changes induced by percutaneous transluminal coronary angioplasty. AM HEART $\mathbf{J}$ 1989;117:769-76.

13. Potkin BN, Roberts WC. Effects of percutaneous transluminal coronary angioplasty on atherosclerotic plaques and relation of plaque composition and arterial size to outcome. Am J Cardiol 1988;62:41-50.

14. Mizuno $\mathrm{K}$, Miyamoto A, Satomura $\mathrm{K}$, Kurita A, Arai $\mathrm{T}$ Sakurada M, Yanagida S, Nakamura H. Angioscopic coronary macromorphology in patients with acute coronary disorders. Lancet 1991;337:809-12.

15. Siegel RJ, Ariani M, Fishbein MC, Chae JS, Park JC, Maurer $G$, Forrester JS. Histopathologic validation of angioscopy and intravascular ultrasound. Circulation 1991;84:109-17.

16. Mizuno K, Satomura K, Miyamoto A, Arakawa K, Shibuya T, Arai T, Kurita A, Nakamura H, Ambrose JA. Angioscopic evaluation of coronary-artery thrombi in acute coronary syndromes. N Engl J Med 1992;326:287-91.

17. Rensing BJ, Hermans WR, Strauss BH, Serruys PW. Regional differences in elastic recoil after percutaneous transluminal coronary angioplasty: a quantitative angiographic study. J Am Coll Cardiol 1991;17:34-8B.

18. Mancini GBJ, Simon SB, McGillem MJ. Automated quantitative coronary arteriography: morphologic and physiologic validation in vivo of a rapid digital angiographic method. Circulation 1987;75:452-60.

19. Sherman CT, Litvark F, Grundfest W. Coronary angioscopy in patients with unstable angina pectoris. N Engl J Med 1986; 315:913-9

20. Siegel RJ, Fishbein MC, Chae JS, Helfant RH, Hickey A Forrester JS. Comparative studies of angioscopy and uitrasound for the evaluation of arterial disease. Echocardiography 1990;7:495-502.

20a. Den Heijer P, Foley DP, Hillege HL, Lablanche JM, Van Dijk RB, Franzen D, Morice MC, Serra A, De Scheerder I, Serruys
PW, Lie KI. The "Ermenonville" classification of observations at coronary angioscopy-evaluation of intra- and interobserver agreement. Eur Heart J 1994;15:815-22.

21. Gerber TC, Erbel R, Gorge G, Ge J, Rupprecht HJ, Meyer J. Classification of morphologic effects of percutaneous transluminal coronary angioplasty assessed by intravascular ultrasound. Am J Cardiol 1992;70:1546-54.

22. Potkin BN, Keren G, Mintz GS, Douek PC, Pichard AD, Satler LF, Kent KM, Leon MB. Arterial responses to balloon coronary angioplasty: an intravascular ultrasound study. J Am Coll Cardiol 1992;20:942-51.

23. Honye J, Mahon DJ, Jain A, White CJ, Ramee SR, Wallis JB, Al-Zarka A, Tobis JM. Morphological effects of coronary balloon angioplasty in vivo assessed by intravascular ultrasound imaging. Circulation 1992;85:1012-25.

24. Ramee SR, White CJ, Collins TJ, Mesa JE, Murgo JP. Percutaneous angioscopy during coronary angioplasty using a steerable microangioscope. J Am Coll Cardiol 1991;17:100-5.

25. White CJ, Ramee SR. Percutaneous coronary angioscopy: methods, findings, and therapeutic implications. Echocardiography 1990;7:485-94.

26. Hermans W, Rensing BJ, Kelder JC, De FP, Serruys PW. Postangioplasty restenosis rate hetween segments of the major coronary arteries. Am J Cardiol 1992;69:194-200.

27. Rensing BJ, Hermans W, Deckers JW, De FP, Tijssen J, Serruys $\mathrm{PW}$. Lumen narrowing after percutaneous transluminal coronary balloon angioplasty follows a near gaussian distribution: a quantitative angiographic study in 1,445 successfully dilated lesions. J Am Coll Cardiol 1992;19:939-45.

28. Serruys PW, Rutsch W, Danchin N, Wijns W, Emanuelsson H, Chappuis $F$, Hermans $W$. Does the new angiotensin converting enzyme inhibitor cilazapril prevent restenosis after percutaneous transluminal coronary angioplasty? Results of the MERCATOR study: a multicenter, randomized, double-blind placebo-controlled trial. Circulation 1992;86:100-10.

29. Kimura T, Nosaka H, Yokoi H, Iwabuchi M, Nobuyoshi M. Serial angiographic follow-up after Palmaz-Schatz stent im plantation: comparison with conventional balloon angioplasty. J Am Coll Cardiol 1993;21:1557-63.

30. Foley DP, Rensing BJ, Vos J, Deckers J. Serruys PW. Is there a need for angiography after 24 hours to assess the results of coronary balloon angioplasty in clinical studies [Abstract]? Circulation 1992;86:I-784.

31. Hanet C, Michel X, Schroeder E. Wijns W. Absence of detect able delayed elastic recoil 24 hours after percutaneous transluminal coronary angioplasty. Am J Cardiol 1993;71:1433-6.

32. Teirstein PS, Schatz RS, Johnson AD, Morris NB, RochaSingh K, DeNardo S.I. Angioscopic versus angiographic detection of thrombus and dissection during coronary interventions [Abstract]. J Am Coll Cardiol 1993;21:79A.

33. Mizuno K, Miyamoto A, Isojima K, Kurita A, Senoo A, Arai $T$, Kikuchi M, Nakamura $H$. A serial observation of coronary thrombi in vivo by a new percutaneous transluminal coronary angioscope. Angiology 1992;43:91-9 